\title{
EDITORIAL
}

\section{ESCREVENDO PARA PUBLICAÇÃO: QUESTÕES ÉTICAS}

A publicação de conhecimento científico começou há mais de 350 anos com a Sociedade Real de Londres (The Royal Society of London). Tal sociedade internacional foi inaugurada pelo Rei Charles da Inglaterra em 1662 e, em 1665, publicou um dos primeiros periódicos científicos, Transações Filosóficas (Philosophical Transactions). ${ }^{1}$ Hoje, existem milhares de periódicos científicos em circulação, fornecendonos informações que tratam da ciência básica à ciência aplicada. Nos periódicos da área de medicina, enfermagem e saúde, buscamos no conteúdo dos artigos que lemos a oportunidade de melhorar nossa prática ou nosso conhecimento acerca de doenças e cuidado ao paciente. Assim, esperamos que o conteúdo publicado seja preciso e seguro na sua contribuição científica. Para ajudar a garantir tal precisão, aplicamos o processo de revisão por pares, no qual os peritos da área avaliam o conteúdo dos manuscritos submetidos ao periódico.

\section{Estabelecendo normas de publicação}

Em 1978, um grupo de editores de um jornal de medicina se encontrou em Vancouver, British Columbia, Canadá com o intuito de desenvolver orientações para a formatação de manuscritos a serem submetidos para seus periódicos. Este grupo iniciou o processo de organização de citações e métodos aplicados às referências dos artigos de periódicos científicos, capítulos de livros e artigos de periódicos diários. ${ }^{2}$ Com o passar dos anos, este grupo prestigioso, hoje denominado o Comitê Internacional de Editores de Periódicos de Medicina (International Committee of Medical Journal Editors - ICMJE), expandiu seu âmbito para orientar também sobre a ética na publicação. O grupo se reune anualmente e revisa suas Normas de Publicação para Manuscritos Submetidos aos Periódicos Biomédicos (Uniform Requirements for Manuscripts Submitted to Biomedical Journals).

Em 1997, um grupo de editores encontrou-se informalmente no Reino Unido para discutir suas preocupações acerca da má-conduta científica. Este grupo foi formalizado, e atualmente é o Comitê de Ética em Publicação (Committee on Publication Ethics - COPE). Em 1999, o COPE emitiu seu Manual para a Boa Prática de Publicação, que trata da organização da pesquisa, dos autores, do processo de revisão por pares, da redundância na publicação, dos deveres dos editores e guias para lidar com má-conduta. ${ }^{3}$ As Guias do ICMJE e do COPE serão usadas na discussão da ética em publicação científica.

\section{Revisão por pares}

A revisão por pares é o processo utilizado por periódicos científicos para a manutenção das normas e para melhorar a qualidade, precisão, leitura e credibilidade do conteúdo a ser publicado. Os revisores são escolhidos a partir de sua experiência na área do conteúdo e no processo de publicação. Os conselhos e sugestões oferecidos por estes e por editores estabelecem os padrões da área. ${ }^{4}$ Muitos periódicos continuam a utilizar o processo "duplo cego" (double blind) em que os autores e revisores não são identificados uns aos outros. Mais do que $90 \%$ dos revisores entrevistados por periódicos de enfermagem preferem este processo e acreditam que o mesmo contribua para a qualidade dos manuscritos publicados. ${ }^{5}$ No decorrer dos anos, este processo de revisão por pares tem identificado preocupações éticas acerca da integridade da pesquisa, proteção para os seres humanos, privacidade, autoridade, 
conflitos de interesse e plágio. Tais preocupações são levadas ao editor para sua avaliação específica, deliberação e ação potencial, uma vez que podem implicar em sério dano aos autores, à integridade científica, ao periódico e à área.

A revisão por pares ajuda o editor na seleção dos melhores manuscritos a serem publicados. Não é fora do comum que os revisores tenham opiniões variadas sobre o mesmo manuscrito. Os revisores são selecionados pelo seu conhecimento no assunto ou nos métodos de pesquisa. Os dois revisores podem discordar, dependendo das suas perspectivas na revisão do manuscrito. Enquanto o conteúdo pode estar correto, o método pode apresentar falhas para atingir às conclusões expressas pelos autores. O editor deve avaliar tais opiniões variadas e tomar decisões sobre a melhor forma de como proceder. Discussões com os revisores podem ajudar a apresentar as recomendações finais aos autores. Embora as sugestões dos revisores sejam de extrema utilidade para os editores, são sugestões e, afinal, os editores não tem obrigação de aderir às mesmas. ${ }^{3}$

\section{Autoria}

A decisão sobre a autoria pode ser delicada no processo de submissão e publicação do manuscrito. Na minha perspectiva, a autoria deve ser decidida no início das discussões, no preparo do manuscrito. Desta forma, futuros problemas potenciais são evitados enquanto os autores procedem com o processo. O ICMJE define como autores aqueles que tenham efetuado contribuições substantivas ao conceito, desenho, análise de dados, composição do manuscrito, como também à aprovação da versão final a ser publicada. ${ }^{6}$ Determinar o primeiro autor é um passo importante na elaboração do manuscrito, pois este autor normalmente assume o papel de liderança em preparar o manuscrito para submissão e posteriormente realizar as revisões propostas. Para evitar disputas, é aconselhado tomar tais decisões acerca da autoria relativamente cedo no processo de desenvolver o manuscrito. ${ }^{3}$

Contribuições adicionais ao manuscrito realizadas por aqueles que não cumprem os requisitos de autoria podem receber um reconhecimento no final do mesmo. Contribuidores consistem naqueles que ofereceram assistência técnica ou em um chefe de departamento que contribuiu com seu tempo e apoio na elaboração do documento. ${ }^{6}$ Esses indivíduos não participaram do planejamento e nem do desenvolvimento do mesmo, portanto, devem receber um reconhecimento ao invés de serem incluídos como autores.

\section{Proteção aos seres humanos, privacidade e confidencialidade}

Como a maioria dos periódicos de medicina e enfermagem tratam de temas relacionados ao cuidado, é importante garantir a proteção dos direitos e da privacidade dos pacientes. Termos de Consentimento Livre e Esclarecido devem ser obtidos antes da divulgação de qualquer informação médica identificável em um relato de caso. Os nomes, iniciais ou fotos dos pacientes não devem ser usados a não ser que o paciente, sua família ou responsável assinem um termo de consentimento escrito de que concordam com a publicação das informações. ${ }^{2}$ Tal termo deve ser mantido pelos autores, como também pelo periódico. O consentimento livre e esclarecido deve ser indicado no artigo publicado, sendo que muitos periódicos agora requerem o mesmo para proteger a privacidade dos individuos. Quando o consentimento livre e esclarecido não puder ser obtido, o Comitê de Ética da instituição deve revisar o manuscrito para determinar se é eticamente aceitável. ${ }^{3}$ Muitos editores de periódicos pedirão uma aprovação ética da instituição na impossibilidade da assinatura do termo de consentimento.

A maioria dos periódicos científicos solicita a informação no corpo do manuscrito, atestando a aprovação do Comitê de Revisão Institucional (Institutional Review Board), ou Comitê de Ética da instituição, quando o estudo envolve seres humanos ou animais. As Normas Consolidadas para Relatar Ensaios Clínicos (Consolidated Standards of Reporting Trials - CONSORT) possui um checklist para os autores submeterem os resultados de ensaios clínicos randomizados controlados. Este checklist também trata da proteção para os seres humanos. Os periódicos são convidados a apoiar as recomendações do CONSORT. Ao apoiá-las, espera-se que os autores sigam as diretrizes do CONSORT no desenvolvimento dos seus manuscritos no caso de um estudo randomizado controlado. ${ }^{7}$ 


\title{
Conflito de interesse
}

Os autores são obrigados a relatar quaisquer relações pessoais ou financeiras que poderiam afetar a objetividade da sua publicação. ${ }^{6}$ Isto é normalmente solicitado pelo periódico, e deve ser incluso na página do título do manuscrito submetido para publicação. Fontes de apoio financeiro à pesquisa ou ao desenvolvimento do manuscrito também devem ser relatadas. Tais declarações aumentam a confiança do público e a credibilidade no processo de revisão por pares, e na transparência da publicação científica. ${ }^{6}$

\section{Discussão}

A publicação em um periódico científico que utiliza o processo de revisão por pares pode ter se tornado mais complexo ao longo dos anos, porém, tem se tornado mais confiavel. Quando nós alteramos nossa prática a partir dos relatos publicados, temos que ter certeza de que a ciência é válida e que as considerações éticas tem sido revisadas cuidadosamente. A autoria tem gerado um potencial para disputa entre aqueles que desejam publicar seu trabalho. As normas produzidas por grupos de consenso, tais como a ICMJE, COPE e CONSORT oferecem um processo claramente definido para fortalecer a publicação de artigos à altura dos padrões de ética e pesquisa. Os periódicos que apoiam tais esforços terão sucesso na produção de relatos ao serem valorizados e aceitos por profissionais de saúde na prática e pela comunidade de autores produtores de conhecimento científico. Ao aderir a estes padrões e critérios éticos, aumentamos a credibilidade do processo através das contribuições publicadas que realmente contribuem para guiar a assistência aos pacientes.

\author{
Linda Ohler, MSN, RN, CCTC, FAAN \\ Editora, Progress in Transplantation and Clinical Administrator Transplant Institute, \\ Georgetown University/Washington, DC, EUA
}

\section{REFERÊNCIAS}

1. The Royal Society, $350^{\text {th }}$ anniversary [online], 2010 [acesso 2010 Apr 18]. Disponível em: http:/ / royalsociety.org/

2. International Committe of Medical Journal Editors. Uniform requirements for manuscripts submitted to biomedical journals [online]. [acesso 2010 Apr 18]. Disponível em: http://www.icmje.org/sop_1about.html

3. Committee on Publication Ethics. Guidelines on good publication practice. [acesso 2010 Apr 18]. Disponível em: http:// publicationethics.org/static/1999/1999pdf13.pdf

4. Rockwell S. Ethics of peer review: a guide for manuscript reviewers [online]. New Have (US): Office of research integrity, US. Department of Health and Human Services; 2005 [acesso 2010 Apr 18]. Disponível em: http:// ori.dhhs.gov/education/products/yale/prethics.pdf

5. Baggs JG, Broome ME, Dougherty MC, Freda MC and Kearny MH. Blinding in peer review, the preferences of reviewers for nursing journals. J Adv Nurs 2008 Oct; 64(2):131-8.

6. International Committe of Medical Journal Editors. Authorship in publications [online]. [acesso 2010 Apr 18]. Disponível em: http://www.icmje.org/ethical_1author.html

7. Consolidated Standards of Reporting Trials. Checklist for reporting in randomized controlled trials [online]. [acesso 2010 Apr 18]. Disponível em: http://www.consort-statement.org/consort-statement/ 